\title{
$\left(\int_{\text {(PSSR }}\right.$ Pakistan Social Sciences Review
}

RESEARCH PAPER

\section{Procrastination and Job Performance of Employees Working in Public and Private Sector Organizations}

\author{
Dr. Zafar Ahmad ${ }^{1}$ Naureen Munir 2 Dr. Munawar Hussain ${ }^{3}$
}

1. Lecturer, Department of Applied Psychology, National University of Modern Languages, Islamabad, Pakistan

2. Lecturer, Department of Applied Psychology, National University of Modern Languages, Islamabad, Pakistan

3. Assistant Professor, Area Study Centre, Quaid-i-Azam University, Islamabad, Pakistan

\section{PAPER INFO}

Received:

March 15, 2021

Accepted:

June 25, 2021

Online:

June 30, 2021

Keywords:

Job Performance,

Procrastination,

Public and Private

Sector

*Corresponding

Author

zaahmad@numl. edu.com

\section{ABSTRACT}

Temporal motivation theory and job resource demand model are widely applied framework to understand procrastination and Job performance of employees in organizational settings. The endeavor of the current research is to understand the moderating role of employee job sector (Public/Private) among procrastination and job performance. Job performance has several determinants where procrastination is one of the factors affecting job performance (Schmitt \& Hunter,2004).Purposive sampling technique was applied based on cross sectional approach. Tuckman's procrastination scale (TPS; Tuckman, 1991) and job performance scale (JPS; Wright, Kacmar, Mcmahan \& Deleeuw, 1995) were used on the sample of 400 employees working in public and private organizations.The correlation as well as moderation analysis were carried out to investigate the study data. Findings demonstrate the relationship of procrastination and job performance whereas job sector is performing moderating role among study variables. The results support the temporal motivation and job demand resource model

\section{Introduction}

Organizations face significant loss due to delayed work and job performance issues of employees. This poses a question to explore procrastination and job performance of employees in organizations. Nothing is so fatiguing as the eternal hanging on of an uncompleted task, procrastination have been found adverse determinant of job performance (Pirson, 2014), and results have been wide spread from individual to social and domestic to professional life .According to Freud, the delight standard may be in charge of deferring one may want to evade negative feelings and to defer the upsetting exercises. The conviction that you work better under pressure gives an extra inspiration to defer of assignments. Some analyst 
refers to such conduct as a system to address the nervousness connected with beginning or finishing any undertaking choice.Regarding the causes of procrastination there are two theoretical perspectives. The first is that procrastination is the personality trait that remains stable overtime and across situation (Elliot,2002).The other perspective used to explain procrastination is a result of environmental and contextual factors that may change overtime. One such situation ist emporal proximity or how soon the deadline for completion is individual are likely to procrastinate more on task that are further away temporary (Frederick, S., Loewenstein, G., \& O'Donoghue, T, 2002). Another situational variable as a cause of procrastination is the aversive nature of task. Steel (2007) claims that task that are less appealing are more postponed in favors of more appealingtask.

Procrastination is failure of self-regulation which badly effect performance and well-being (Steel,2007). Steel recently argued in his book "The Procrastination Equation" that information technology especially social media is turning people to immediate gratification however ageand responsibilities make them sensitive towards procrastination. For people, procrastination is not only an occasional issue but in fact disturbing their routine life and potentials.

Procrastination heavily cost to the companies, as per research it charge about $\$ 10,000$ for a single employee annually (D'Abate \& Eddy, 2007; Steel, 2011). Procrastination and self- reported financial success are negatively associated (Mehrabian, 2000) symptoms of Attention Deficit Hyper activity Disorder (ADHD), showed issues like distraction and disorganization at work (Re Snick, 2005) whereas ADHD reduced earnings by approximately 30\% (Fletcher,2013).

Procrastination leads to low performance, procrastinatorsspend more time in non-work related activities then related one. Face lower level of concentration and more fatigue, to complete their routine work, work for longer hours and in hurry for their tasks which cause errors and come acrossperformance issues at job. A chronic procrastinator is less likely to be employed (Barrick, et al., 2013). Procrastination have different effects on the effectiveness of organizations and individuals, so it iscontagious to identify various causes and reasons to address it (Beheshtifar, M., Hossenifar, H., \& Moghadam, M.N., 2011). Procrastination badly effect performance of employees (Steel, 2007).

\section{Literature Review}

Hubner (2012)analysed and debated upon aftermaths of procrastination and drastic need of decisive leadership. Klingsieck's (2013) study evaluated the distinction between procrastination in different life-domains including academic and work, everyday routines and obligations, health, leisure, family and partnership and social contacts. Deterioration in efficiency and performance was found nearly in all domains. Herweg and Muller (2011) examined that issues of self-control may reduce a person's performance and well-being, effectively curtails the chances of 
procrastination, structure workload more efficientlywhich in turn leads to better performance.

Hammer and Ferrari (2002) classified the workers and then explored the prevalence of procrastination among them. The results showed that "white-collar" workers reported significantly higher scores on all three forms of chronic procrastination than "blue-collar" workers which reflects the unique pattern that professional employees reported procrastination more frequently than unskilled workers.

Nguyen, Steel, and Ferrari (2013), explored procrastination's role in workplace on large sample of 22,053 individuals and found that high levels of procrastination was associated with lower salaries, shorter durations of employment, and a greater likelihood of being unemployed rather than working full-time. Women tend to procrastinate less than men, evidently giving women an employment advantage. Furthermore, researchers found that procrastinators tend to have jobs that are lower in intrinsically rewarding qualities.

Recently in Pakistan, Aziz and Tariq (2013) explored that public sector executives were significantly higher on decisional procrastination as compared to private executives. Higher level of decisional procrastination and lower internal locus of control was reported among less experienced executives, job tenure executives who were moreexperienced reported significantly higher level of internal locus of control and lower level of decisional procrastination. Mohsin and Ayub (2014) found negative association between procrastination and job satisfaction among teachers in Karachi, Pakistan. They found the procrastination and delayed gratification predicted work stress which effect work satisfaction whereas when the teachers are not procrastinating on their job, they will be more satisfied with their job and less stressed.

Temporal motivation theory (TMT) is ingrained with termed pico-economic orhyperbolic discounting (Ainslie \& Haslam; 1992) explained decision making processes. Temporal motivation theory suggests that an individual prefer the activities which lead to maximum utility for specific time. It means individuals have a tendency to procrastinate low utility tasks. It has been derived from picoeconomics that TMT maintain pico-economic component of utility, expectancy, value, sensitivity to delay and time delay (Steel, 2007; Steel \& Konig,2006).

Steel and Konig (2006) addressed that TMT agree with procrastination grounded theory of Schraw, Wadkin and Olafson (2007). Studies suggest that indistinct directions, less benefits and deadlines are equivalent to expectancy, value and sensitivity to delay respectively when connected to the temporal motivation theory. Blurred task and expectations lead slow self-confidence for task completion, rewards associated with tasks are satisfactory factors which motivate to perform. Moreover, unappealing incentive lead to delay because task has not owned comparable proportion and time limit become external influence. 
The Job Demands-Resources (JD-R) model emphasized on employee issues related to burnout, engagement and subsequently organizational performance (Bakker \& Demerouti, 2007; Demerouti et al., 2001). The model highlighted the supposition that companies and organizations have their own issues and factors of well-being categorized as job demands and resources. Job demands factors include time pressures, a heavy workload, a stressful working environment, role ambiguity, emotional labor, and poor relationships. Job resources factors includes physical, societal, or structural factors that assist in goal achievement and stress reduction. These factors also comprised of autonomy, work relationships, chances for progress, training, mentoring and learning opportunities.

The model gave a comprehensive approach applicable for different occupations.Research gave indication for presence of two concurrent methods. High job demands consumed energies which leads exhaustion and impair mental and physical health. Apart from this, job resources are the motivational processes which foster employee involvement and performance at workplace. Numerous researched have found that job resources act like shield to control influences of job demandsonstress-reactions. Research findings also suggested that job resources have potential to motivate especially with high job demand scenarios and help to enhance performance of employees at work. It is very obvious that when employee have resources (colleagues' support or having ability to one's own work) they tried to work beyond routine and focuses on goals and targets to accomplish (Wrzesniewski \& Dutton, 2001) on the other hand when employees having less resources at job additional performance related with their role sufferbadly.

The present research was meant to explore procrastination and job performance among public and private sector employees. Employees are valuable asset and important resource for an organization. Employees' development and efficiency issues can't be neglected. Procrastination of employees is an other notable issue which is decreasing employee as well as organizational performance (Hammer \& Ferrari, 2002; Klatt, Wise \&Fish, 2012; Klingsieck, 2013; Morrison \& Jha, 2011; Vugt, \& Jha,2011).

In Pakistan most of research work on procrastination and performance is beingdoneonthedisciplineofacademiaandeducationfocusingonacademicprocrastina tionand academic performance of students at college or university level (Hussain \& Sultan;2010, Khan, Arif, Noor \& Muneer; 2014, Saleem, Bashir, Amin \& Noor; 2016, Zahra \& Riaz; 2017, Afzal \& Jami; 2018, Zubair, Kamal, Artemeva; 2018), while organizational context needs attention. After reviewing literature, a major gap with reference to procrastination and performance is identified this needs to be address in organizational setup.

\section{Hypotheses}

Following hypotheses were formulated to study procrastination and job performance among employees. 
1. There is a positive relationship between Procrastination and job performance.

2. Public sector employees will be high on procrastination and low on job performance then private sector employees.

\section{Material and Methods}

\section{Sample}

The sample comprised of 400 employees (Male $=305$ and Female $=95$, Permanent $=213$ and Contractual $=187$, Public $=71$ and Private $=328)$ fromdifferent organizations of Telecom Sector. For the purpose of data collection the employees initially contacted were 475 but depending upon the rate of return and thoroughly filled, 400 questionnaires were sortedoutas sample. Response rate of participants out of 100 was $81.33 \%$ employees and on the total 75 questionnaires were not returned. The employees who participated in the research were from information technology, engineering, accounts/finance and HR/administration department of the telecom organizations from Islamabad and Rawalpindi areas of Pakistan. The data were collected through purposive convenient sampling technique with participantsconsent.

\section{Procedure}

For the purpose of data collection, the organizations were contacted. In most of the organizations the human resource department helped in data collection. The complete details regarding research, data collection, confidentiality and usage of the data were shared with the concerned representative of the department. They asked for the questionnaires in first meeting and take some time to review and permission from the head of the department. After clearing their all research related queries, they allowed to collect the data and further guide to the departments and thei remployees. Now the employees were informed about there search and its scope, they are very keen about the confidentiality of data, they were assured that the data will be kept confidential and will only use for university research purpose. Their names, designations, salary etc will not be shared with anyone else. They were also informed that it's voluntary participation so if anyone wants to leave then they have right to leave. They were explained about Tuckman Procrastination Scale (TPS) and Job Performance Scale (JP- S). Some of them took 15-20 minutes to fill the questionnaires and return back whereas some employees took few days. The data were collected as per their convenience. Since job performance was taken from employees and their managers/officers as well, especially care was taken to keep the process blind to avoid any stigmatization orlabeling. 


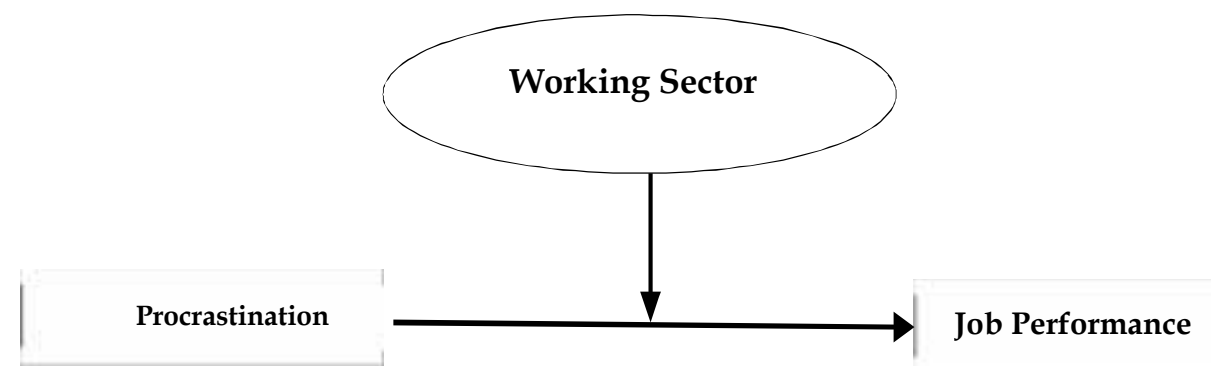

Working Sector As A Moderator Between Procrastination And Job Performance

\section{Results and Discussion}

Table

Moderation impact of the working sector between procrastination and job performance among employees $(N=400)$

\begin{tabular}{|c|c|c|c|c|c|c|c|c|}
\hline & $\mathbf{R}$ & $\mathbf{R} 2$ & $\Delta R$ & $\mathbf{F}$ & coefficient & SE & $\mathbf{t}$ & $\mathbf{P}$ \\
\hline Model Summary & .2034 & .0414 & & 6.4169 & & & & .0003 \\
\hline Constant & & & & & 37.2821 & 6.6945 & 5.5691 & .0000 \\
\hline Working Status & & & & & 10.5995 & 3.9385 & 2.6913 & .0074 \\
\hline TPS & & & & & .2903 & .1731 & 1.6769 & .0943 \\
\hline Interaction & & & & & -.1956 & .1024 & -1.9101 & .0568 \\
\hline TPS $\times$ Working Status & & & & .0078 & 3.6483 & & & .0568 \\
\hline
\end{tabular}

Note: $T P S=$ Tuckman's Procrastination Scale

Findings revealed in moderation with working sector bare the significance on $p=.05$, suggesting working status i.e. private or in public setup interacting with procrastination bring some level of change on job performance. Here interaction of predictor and moderator should be clear by computing t-slopes and mod-graph figure.

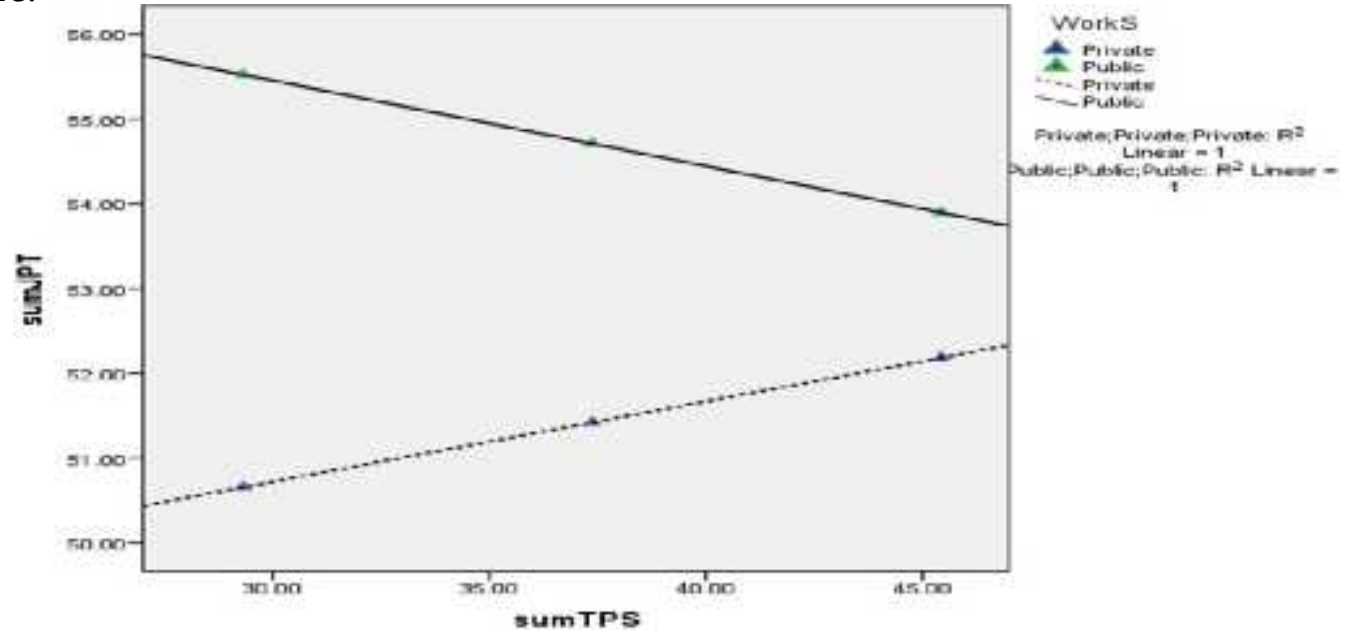


In above mod graph, public sector employees tend to have more procrastination and less job performance as compared to employees working in private sector organization who have less procrastination with overall more job performance.

\section{Discussion}

The proposed research contributes to the organizational psychology literature in two main theoretical domains of procrastination and job performance. The present study has two domains which are procrastination and job performance at workplace. Procrastination is effecting job performance of employees at all level of their work either they are engage in decision making or in routine operational activities of their job. To understand procrastination and job performance at work Temporal Motivation Theory (TMT) and Job-Demand-Resources Model (JD-R) were used as background. Temporal motivation theory suggests that an individual prefer the activities which lead to maximum utility for specific time. It means individuals have a tendency to procrastinate low utility tasks. It has been derived from picoeconomics that TMT maintain pico-economic component of utility, expectancy, value, sensitivity to delay and time delay (Steel, 2007; Steel \& Konig,2006).

The Job Demands-Resources (JD-R) model emphasized on employee issues related to burnout, engagement and subsequently organizational performance (Bakker \& Demerouti, 2007; Demerouti et al., 2001). The model highlighted the supposition that companies and organizations have their own issues and factors of well-being categorized as job demands and resources. Job demands factors include time pressures, a heavy workload, a stressful working environment, role ambiguity, emotional labor, and poor relationships. Job resources factors include physical, societal, or structural factors that assist in goal achievement and stress reduction. These factors also comprised of autonomy, work relationships, chances for progress, training, mentoring and learning opportunities.

The model gave a comprehensive approach applicable for different occupations.Research gave indication for presence of two concurrent methods. High job demands consumed energies which lead exhaustion and impair mental and physical health. Apart from this, job resources are the motivational processes which foster employee involvement and performance at workplace. Numerous researched have found that job resources act like shield to control influences of job demandsonstress-reactions. Research findings also suggested that job resources have potential to motivate specially with high job demand scenarios and help to enhance performance of employees at work. It is very obvious that when employee have resources (colleagues' support or having ability to one's own work) they tried to work beyond routine and focuses on goals and targets to accomplish (Wrzesniewski \& Dutton, 2001) on the other hand when employees having less resources at job additional performance related with their role sufferbadly.

Results were found that working sector is playing role in procrastination and job performance of employees. This means that employees of public and private 
organizations have differences on procrastination and performance. However the moderation with working sector bare the significance on $\mathrm{p}=.05$, suggesting working status i.e. private or in public/government setup interacting with procrastination bring some level of change on job performance. The mod graph, public/government sector employees tend to have more procrastination and less job performance as compared to employees working in private sector organization who have less procrastination with overall more job performance. The public sector employees are procrastinating more as compare to private sector employees whoaffect their performance and overall productivity of the organization.

Prevalence of procrastination among public sector employees indicates that employees in public sector organization are delaying their assigned tasks more then private sector employees which is affecting the productivity of organization as a result the impression of public sector organizations is generally not good. There could be number of factors for instance their permanent job status with the organization, overstaffing, ambiguous job descriptions etc. During research it has been discussed with employees of both public and private sector organizations and the main factor which came across was the linkage of performance with reward and acknowledgement. In public sector employees are unable to find any link of performance with reward or appreciation which is one of the reasons to procrastinate at work. Contrary to public sector, in private organizations employees are getting regular feedback from their supervisors or the organization about their work, targets and accomplishments which motivate them to perform assigned tasks timely and not to procrastinate.

\section{Conclusions}

These findings suggest that procrastination and job performance of public and private sector employees have impact which shows public sector employees have more procrastination tendencies which is affecting their job performance. Therefore, overcoming procrastination tendencies of public sector employees their job performance could be stimulated.Results showing that public and private sector employees are performing differently having different at procrastination. There is strong need to explore further about public and private sector employees on procrastination and job performance, which are the organizational factors contributing, causing and affectingprocrastination and job performance

The study suggests the dire need to work on serious interventions and training programsas evidenced by researches showing that procrastination appears to provide wide range of outcomes, rangingfrom stress, low self-esteem to performance at work. Such issues should be instigated by professional organizations that are facing performance detrimental challenges in present day workenvironment(Goodetal., 2016; Glomb, Duffy, Bono, \& Yang, 2011). It is hoped that this work will add to theunderserved literature that seeks to provide insight into the perceptions and expectations of the facilitators of organizations as well as provide insight into the barriers that surface, and the conditions that sustenance the 
successful execution of programs to address procrastination and job performance in organizations.

\section{Recommendations}

One of the challenges to employees in any workplace setting is related to consistency in job performance. Despite of advance technological progress in human performance and efficiency, human factor is still essential in all cases and it sure deemed certain ramifications on its part. This study is one such effort to establish correlational dynamics across the procrastination and job performance and how working sector as moderator is impacting it. Professional trainings in these both areas are relatively untouched zones and results elaborated that procrastination is a significant factor impact performance negatively thus employees' engagement to overcome procrastination and enhancing job performance strategies could serve as the effective means. Furthermore, employers can take initiative to address personal and contextual factors to avoid the halting lag of procrastination on work setups. 


\section{References}

Afzal, S., \& Jami, H. (2018). Prevalence of academic procrastination and reasons for academic procrastination in university students. Journal of Behavioural Sciences, 28(1).

Beheshtifar, M., Hoseinifar, H., \& Moghadam, M. (2011). Effect procrastination on work-related stress. European Journal of Economics, Finance and Administrative Sciences, 38, 59-64.

Bakker, A. B., \& Demerouti, E. (2007). The job demands-resources model: State of the art. Journal of managerial psychology, 22(3), 309-328.

Balkis, M. \&Duru, E.(2009).Prevalence of Academic procrastination behavior among pre-service teachers, and its relationship with demographic and individual preference. Journal of theory andpractice in education 5(1), 18- 32

Campbell, D.T. (1963). Social attitudes and other acquired behavioural dispositions. In S. Koch (Ed.), Psychology: A study of a science (Vol. 6, pp. 94-172). New York, NY: McGraw-Hill

Campbell, J. J., Dunnette, M. D., Lawler, E. E., \& Weick, K. E. (1970). Managerial behavior, performance, and effectiveness.

D'Abate, C. P., \& Eddy, E. R. (2007). Engaging in personal business on the job: Extending the presenteeism construct.Human Resource Development Quarterly, 18(3), 361-383.

Deci, E. L., \& Ryan, R. M. (1980). The empirical exploration of intrinsic motivational processes. In L. Berkowitz (Ed.), Advances in experimental social psychology (Vol. 13, pp. 39-80). New York: Academic.

Deci, Edward L.; Ryan, Richard M. (2008). Social psychology and self-determination theory: A Canadian contribution. Canadian Psychology, 49(3), 182 185. Retrieved from: http:/ / dx.doi.o rg/10.1037/a0012801

Ellis, A., \&Knaus, W. J. (1977). Overcoming procrastination. New York: Institute for Rational Living.

Ferrari, J. R., Johnson, J. L., \& McCown, W. G. (1995). Procrastination and task avoidance: Theory, research, and treatment. Springer Science \& Business Media.

Gagnon, J., Dionne, F., \& Pychyl, T. A. (2016). Committed action: An initial study on its association to procrastination in academic settings. Journal of Contextual Behavioral Science, 5(2), 97-102. 
Gagnon, J., Dionne, F., \& Pychyl, T. A. (2016). Committed action: An initial study on its association to procrastination in academic settings. Journal of Contextual Behavioral Science, 5(2), 97-102.

Hammer, C. A., \& Ferrari, J. R. (2002). Differential incidence of procrastination between blue and white-collar workers. Current Psychology, 21(4), 333-338.

Hammer, C. A., \& Ferrari, J. R. (2002). Differential incidence of procrastination between blue and white-collar workers. Current Psychology, 21(4), 333-338.

Hussain, I., \& Sultan, S. (2010). Analysis of procrastination among university students. Procedia-Social and Behavioral Sciences, 5, 1897-1904.

Howell, A. J., \&Buro, K. (2010). Relations among mindfulness, achievement-related self-regulation, and achievement emotions. Journal of Happiness Studies, 12(6), 1007-1022.

Klingsieck, K. B. (2013). Procrastination in different life-domains: Is procrastination domain specific?,Current Psychology, 32(2), 175-185.

Schouwenburg, H. C., Lay, C. H., Pychyl, A., \& Ferrari, J. R. (2004). Procrastination in academic settings and the Big Five model of personality: A metaanalysis. Counseling the procrastinator in academic settings, 29-40.

Schmidt, F. L., \& Hunter, J. (2004). General mental ability in the world of work: occupational attainment and job performance. Journal of personality and social psychology, 86(1), 162.

Shonin, E., Van Gordon, W., Dunn, T. J., Singh, N. N., \& Griffiths, M. D. (2014). Meditation Awareness Training (MAT) for work-related wellbeing and job performance: A randomised controlled trial. International Journal of Mental Health and Addiction, 12(6), 806-823.

Sirois, F. M., \& Tosti, N. (2012). Lost in the moment? An investigation of procrastination, mindfulness, and well-being. Journal of Rational-Emotive $\mathcal{E}$ Cognitive-Behavior Therapy, 30(4), 237-248.

Tice, D. M., \& Bratslavsky, E. (2000). Giving in to feel good: The place of emotion regulation in the context of general self-control. Psychological inquiry, 11(3), 149159.

Wrzesniewski, A., \& Dutton, J. E. (2001). Crafting a job: Revisioning employees as active crafters of their work. Academy of management review, 26(2), 179-201. 